\title{
Relation between serum amylin level and epilepsy
}

\author{
Necla Benlier ${ }^{1 *}$ (D), Gokhan Ozer ${ }^{2}$ (D) and Nuri Orhan ${ }^{3}$
}

\begin{abstract}
Background: Epilepsy is a neurological disorder characterized by convulsions. Identification of biological pathways underlying epilepsy and novel genes may shed light on the pathogenesis of epilepsy as well as new targets for treatment.

Objectives: Amylin is cosecreted with insulin from the pancreatic $\beta$-cells in a pulsatile manner as a response to nutrient stimuli. In vitro studies have shown the neurotoxicity potential of amylin. We aimed to investigate serum amylin levels between epilepsy patients and a healthy control group.
\end{abstract}

Subjects and methods: For this study, 45 patients with epilepsy and 60 healthy controls were enrolled. Routine blood analysis and electroencephalography scan were performed for all participants. Five cc venous blood sample was collected from each participant. Sera were isolated and stored at $-80^{\circ} \mathrm{C}$ until the time of amylin analysis with the enzyme-linked immunosorbent assay.

Results: Gender distribution of the two groups was as follows: $44.4 \%$ males and 55.6\% females among epileptic patients and $53.3 \%$ males and $46.7 \%$ females for control subjects.

Body mass index was $23.09 \pm 3.99 \mathrm{~kg} / \mathrm{m}^{2}$ for epileptic patients and $26.29 \pm 4.83 \mathrm{~kg} / \mathrm{m}^{2}$ for controls, with a statistically significantly higher body mass index in control subjects ( $p$ < 0.001 ). With regard to serum amylin levels, a statistically significant difference was observed between the two groups ( $\left.p^{<} 0.001\right)$. The median serum amylin concentration was $226.62 \mathrm{ng} / \mathrm{ml}(69.49-6961.19$ (min-max)) for epileptic patients and $103.66 \mathrm{ng} / \mathrm{ml}(37.42-607.11$ (min-max)) for controls ( $p^{<}$0.001).

Conclusion: In the present study, a significant difference was observed between patient and control groups in serum amylin concentrations, which were considerably higher in epileptic patients.

Keywords: Epilepsy, Amylin, Amyloid beta, Amyloidogenic peptide

\section{Introduction}

Recent studies reported that 70 million people have epilepsy worldwide, and about $90 \%$ of them reside in developing countries [1].

Epilepsy is a neurological disorder characterized by convulsions [2]. Epileptic seizures may result from transient interruption of normal brain function. Several factors including illnesses, genetic predisposition, and environmental triggers have been implicated in its etiology [2, 3]. Antiepileptic agents are not effective for all types of epilepsy or all patients, and they are associated with side effects [4-6]. Apart from

\footnotetext{
* Correspondence: nbenlier@hotmail.com

${ }^{1}$ Department of Medical Pharmacology, Faculty of Medicine, SANKO

University, 27090 Gaziantep, Turkey

Full list of author information is available at the end of the article
}

antiepileptic agents, the ketogenic diet may be effective in the non-pharmacological treatment of refractory childhood epileptic seizures. The ketogenic diet is a diet rich in fats and poor in carbohydrates that mimic the effects of starvation in the body $[7,8]$. Recently, studies have shown that the ketogenic diet is also an effective alternative therapeutic option for adults, and there are ongoing studies that investigate its long-term effects [9].

Identification of biological pathways underlying epilepsy and novel genes may shed light on the pathogenesis of epilepsy as well as new targets for treatment.

Amylin is cosecreted with insulin from the pancreatic $\beta$ cells in a pulsatile manner as a response to nutrient stimuli [10]. Amylin is synthesized as a propeptide precursor prepro IAPP (Islet Amyloid Polypeptide), and a precursor 
of 67 amino acids, pro IAPP, is formed after the removal of the signal peptide from this molecule [11].

Amylin is colocalized and cosecreted with insulin by pancreatic beta cells. Factors involved in insulin secretion also affect amylin secretion. While glucose, arginine, and carbachol activate amylin, somatostatin has an inhibitory effect on amylin secretion [10].

In addition to pancreas, amylin secretion was also demonstrated in trigeminal ganglion, dorsal root ganglia, spinal trigeminal tract, and perivascular fibrils $[12,13]$. Amylin crosses the blood-brain barrier, and amylin binding sites are present in many cerebral regions [14-16]. Amylin is known to interact with the insulin- signaling cascade [17].

Amylin, an amyloidogenic peptide of 37-aminoacids, was shown to share biophysical properties with amyloidbeta $(A \beta)$ peptide that forms insoluble aggregates in the brain of patients with Alzheimer's disease (AD). Using embryonic rat hippocampal cultures, amylin was found to induce neurotoxicity similar to that previously observed with $A \beta$ (1-40). However, rat amylin showed negligible neurotoxicity despite having $95 \%$ sequence similarity to human amylin [18].

In a separate study, hyperamylinemia caused by excessive amylin production due to gene expression alterations in the cerebral cortex of mice was associated with deleterious effects in an AD mouse model [19].

The toxic species of human amylin are soluble oligomers. Amylin oligomers alter membrane $\mathrm{Ca}^{2+}$ homeostasis and viability of various cells including astrocytes and neurons [20]. Additionally, oligomeric amylin causes elevated plasma free fatty acid levels by stimulating lipolysis, activates renin-angiotensin-aldosterone system, and promotes inflammatory and oxidative stress [20-22]. Amylin oligomerization and amylin deposition in the pancreas were found in patients with type 2 diabetes mellitus [17]. In a number of studies, increased plasma amylin concentrations have been demonstrated in many disorders such as hypertension, hyperparathyroidism, and renal failure [23-25].

Recent experimental evidence suggests that hyperamylinemia induces toxicity in peripheral organs $[20,26]$. A forementioned studies showed that increased serum amylin levels were associated with neurodegeneration and brain injury. Since epilepsy is a neurodegenerative disorder, we aimed to determine serum amylin levels in epileptic patients in comparison with healthy control subjects.

In this study, we aimed to investigate serum amylin levels in epilepsy patients and a healthy control group.

\section{Subjects and methods}

The study was conducted with a total of 105 subjects including 45 epileptic patients presenting to SANKO
University Sani Konukoğlu Research and Practice Hospital and 60 healthy controls. Patients were newly diagnosed with epilepsy (confirmed through routine workup including EEG (The NicoletOne v32 EEG system) and blood biochemistry ) and enrolled in the study regardless of the epilepsy subtype. Epilepsy grading of the study patients was performed based on the International League Against Epilepsy (ILAE) 1981 classification.

Study inclusion criteria, no previous diagnosis of epilepsy, no prior use of antiepileptic medications, naive to drugs used for the treatment of neuropathic pain (gabapentin, pregabalin).

Study exclusion criteria, patients diagnosed with diabetes mellitus or treated with antidiabetic drugs for any reason, patients with an abnormal brain magnetic resonance imaging, patients taking medications on a regular basis for a chronic condition, and patients with a neurodegenerative disease such as Alzheimer's disease or Parkinson's disease.

Approval was obtained from the ethics committee of SANKO University clinical researches before the study (April 2019). Written informed consent was obtained from all patients and control subjects prior to initiation of the study. All participants were informed about the nature and scope of the study. Routine blood analysis and electroencephalography scan were performed for all participants. Brain magnetic resonance imaging was conducted when deemed necessary. The results of the neuroimaging examinations with a 1.5 Tesla brain magnetic resonance imaging. Five cc venous blood sample was collected from each consenting participant into plain biochemistry tubes. Sera were isolated and stored at $80^{\circ} \mathrm{C}$ until the time of amylin analysis with the enzymelinked immunosorbent assay. The serum amylin level was determined by Elisa method (Human (Amylin) Elisa kit Catalogue No. 201-12-0017).

Statistical analysis were performed using the Statistical Package for the Social Sciences (IBM SPSS Statistics 22.0/2013, New York City, USA). Kolmogorov-Smirnov test showed a normal distribution of body mass index and an abnormal distribution of age and plasma amylin levels among the study and control groups. MannWhitney $U$ test was used for variables with a nonnormal distribution and Student's $t$ test for variables with a normal distribution. The $\chi^{2}$ test was used to analyze gender difference between study groups. A $p$ value less than 0.05 was considered statistically significant.

\section{Results}

The study enrolled 45 patients diagnosed with epilepsy and 60 healthy controls. Gender distribution of the two groups was as follows: $44.4 \%$ males and $55.6 \%$ females among epileptic patients and $53.3 \%$ males and $46.7 \%$ 
females for control subjects. There was no significant difference with respect to gender between the study groups $(p=0.4)$ (Table 1). Body mass index comparison between the two groups showed that mean ( \pm standard deviation) body mass index was $23.09 \pm 3.99 \mathrm{~kg} / \mathrm{m}^{2}$ for epileptic patients and $26.29 \pm 4.83 \mathrm{~kg} / \mathrm{m}^{2}$ for controls, with a statistically significantly higher body mass index in control subjects $\left(p^{<} 0.001\right)$ (Table 1). Age comparison of the two groups showed that median age was 28 years (min 18max 60) for epileptic patients and 36 years ( $\min 18-\max$ 70) for controls. No significant difference was found between the study groups $(p=0.07)$ (Table 1$)$.

With regard to serum amylin levels, a statistically significant difference was observed between the two groups ( $p^{<}$0.001) (Table 1). The median serum amylin concentration was $226.62 \mathrm{ng} / \mathrm{ml}(69.49-6961.19$ (min-max)) for epileptic patients and $103.66 \mathrm{ng} / \mathrm{ml}(37,42-607,11$ $(\min -\max ))$ for controls (Table 1$)$. Table 2 shows the data for gender and serum amylin levels in epileptic patients and healthy controls. As can be seen from the table, there were no significant differences in serum amylin concentrations between the study groups in relation to gender (epileptic patients, $p=0.5$; control subjects, $p=0.2$ ).

\section{Discussion}

The islet amyloid polypeptide (IAPP) or amylin is a peptide hormone composed of 37 amino acid residues. This hormone is synthesized by pancreatic islet beta cells. Amylin is secreted together with insulin and has a key role in the regulation of blood glucose level. Studies have shown that amylin and insulin are not only involved in glucose dysregulation but also have harmful toxic effects in patients with type 2 diabetes mellitus [27]. Deleterious effects of hyperamylinemia are related to conversion of amylin into amyloids [20]. The toxic species of human amylin are soluble oligomers. These oligomers alter $\mathrm{Ca}^{2+}$ homeostasis and viability of various cells such as astrocytes and neurons. Moreover, oligomeric amylin affects the cardiovascular system by inducing lipolysis. Elevated plasma free acid levels promote inflammation and oxidative stress via advanced glycation end products receptors (RAGE) [26].
Through its several hormones, particularly glucagon and insulin, the pancreas maintains blood glucose levels within a narrow range under normal physiological conditions. Amylin secreted by the pancreas is a critical component of this multihormonal system which regulates both glucose metabolism and food intake [28, 29]. Studies showed development of obesity and insulin resistance associated with low serum amylin levels and the effects on pramlintide, an amylin analogue used for the treatment of obesity, on body mass index [29].

In the present study, greater body mass index was found in the control subjects who had lower amylin levels compared with epileptic patients. This finding is consistent with relevant literature.

Human amylin is a very aggressive amyloid-forming peptide. More than $95 \%$ of insulin-resistant patients that develop overt type 2 diabetes mellitus exhibit amylin amyloids in the pancreas [2]. The initial oligomerization process may involve proamylin and is associated with chronic hyperglycemic stress. Additionally, oligomerized amylin accumulates in the heart and kidneys, precipitating diabetic heart failure [26, 30].

Jackson $\mathrm{K}$ and colleagues showed that hyperamylinemia coincides with morphological changes of tissue and bending of the capillaries, leading to neurodegeneration of the cerebral blood vessels [31]. In the same study, amylin accumulation in the temporal lobe gray matter of diabetic patients with $\mathrm{AD}$, non-diabetic patients with $\mathrm{AD}$, and healthy controls was examined, and amylin deposition was observed in diabetic patients but not in healthy controls. Interestingly, they observed amylin accumulation in the brain of non-diabetic patients with $\mathrm{AD}$ and attributed this finding to insulin resistance or aging.

In one study by Mulder and colleagues detected amylin-like immunoreactivity in small to medium size nerve cell bodies in the dorsal root ganglia, dorsal horns of the spinal cord and trigeminal ganglion [32].

In the present study, a significant difference was observed between patient and control groups in serum amylin concentrations which were considerably higher in epileptic patients. We excluded patients with established diabetes mellitus, patients using antidiabetic drugs for any reason, patients receiving multiple therapies for

Table 1 Comparison of study variables between epileptic patients and controls

\begin{tabular}{llll}
\hline & Epilepsy group (number of individuals $=45)$ & Control group (number of individuals $=60)$ & $p$ value \\
\hline Gender, male/female & $20 / 25,44.4 \% / 55.6 \%$ & $32 / 28,53.3 \% / 46.7 \%$ & $0.4^{*}$ \\
BMl $\left(\mathrm{kg} / \mathrm{m}^{2}\right.$ ), mean \pm standard deviation & $23.09 \pm 3.99$ & $26.29 \pm 4.83$ & $<0.001^{* *}$ \\
Age (years), median (min-max) & $28(18-60)$ & $36(18-70)$ & 0.07 \\
Amylin $(\mathrm{ng} / \mathrm{ml})$, median (min-max) & $226.62(69.49-6961,19)$ & $103.66(37.42-607,11)$ & $<0.001$ \\
\hline
\end{tabular}

The Mann-Whitney $U$ test was used for statistical analysis

*The chi-square test was used for statistical analysis

**Based on Student's $t$ test 
Table 2 Association between serum amylin levels and gender among epileptic patients and controls

\begin{tabular}{|c|c|c|c|}
\hline & \multicolumn{2}{|c|}{ Amylin (ng/ml), median (min-max) } & \multirow{2}{*}{$\begin{array}{l}p \\
\text { value }\end{array}$} \\
\hline & Male & Female & \\
\hline Epilepsy group (number of men = 20; number of women $=25$ ) & $191.18(69.49-3526.68)$ & $247.98(70.25-6961,19)$ & 0.5 \\
\hline Control group (number of men $=32 ;$ number of women $n=28$ ) & $114.40(37.42-447.41)$ & $92.52(49.92-607.11)$ & 0.2 \\
\hline
\end{tabular}

The Mann-Whitney $U$ test was used for statistical analysis

epilepsy or medications for a chronic condition on a regular basis and patients with a neurodegenerative disease such as Alzheimer's or Parkinson's disease. Our study sample consisted of patients with newly diagnosed epilepsy. Despite this, serum amylin levels of these patients were significantly higher in comparison with those of control subjects.

The present study has two limitations including small sample size and failure to stratify patients based on epilepsy subtypes. There is a need for further studies that involve a greater number of patients and taking into account epilepsy subtypes.

\section{Conclusion}

In this study, a significant difference was observed between patient and control groups in serum amylin concentrations. A major aspect of our study suggests that serum amylin levels and hyperamylinemia play a role in the pathogenesis of epilepsy. Moreover, this study may help explain why some epilepsy patients derive benefit from the ketogenic diet.

\section{Acknowledgements}

Not applicable.

\section{Authors' contributions}

All authors read and approved the final manuscript. BN made the literature search, planned, and wrote. OG provided the voluntary patients. ON evaluated amylin levels in serum.

\section{Funding}

The authors declared that this study has received no financial support.

\section{Availability of data and materials}

The datasets used and/or analyzed during current study are available from the corresponding author on reasonable request.

\section{Ethics approval and consent to participate}

All procedures performed in studies involving human participants were in accordance with the ethical standards of the institutional and/or national research committee and with the 1964 Helsinki declaration and its later amendments or comparable ethical standards. Ethics approval was obtained from the Institutional Ethics Committee of SANKO University before the conduct of the study ( Day:01/2019; Decision number:04). Informed consent was obtained from all individual participants included in the study.

\section{Consent for publication}

Not applicable.

\section{Competing interests}

The authors declare that they have no competing interests.

\section{Author details}

${ }^{1}$ Department of Medical Pharmacology, Faculty of Medicine, SANKO University, 27090 Gaziantep, Turkey. ${ }^{2}$ Department of Neurology, Faculty of Medicine, SANKO University, Gaziantep, Turkey. ${ }^{3}$ Medical Park Hospital Department of Biochemistry, Gaziantep, Turkey.

Received: 21 March 2019 Accepted: 18 February 2020

Published online: 10 March 2020

\section{References}

1. Ngugi AK, Bottomley C, Kleinschmidt I, Sander JW, Newton CR. Estimation of the burden of active and life time epilepsy: a meta-analytic approach. Epilepsia. 2010;51(5):883-90.

2. Fisher RS, Harding G, Erba G, Barkley GL, Wilkins A. Photic- and patterninduced seizures: a review for the Epilepsy Foundation of America Working Group. Epilepsia. 2005;46(9):1426-41.

3. Mulley JC, Scheffer IE, Harkin A, Berkovic SF, Dibbens LM. Susceptibility genes for complex epilepsy. Hum Mol Genet. 2005;14 Spec No. 2:R243-R249.

4. Brodie M, Covanis T, Gil-Nagel A, Lerche H, Perucca E, Sills G, et al. Antiepileptic drug therapy: does mechanism of action matter? Epilepsy Behav. 2011;21(4):490.

5. Perucca $\mathrm{E}$, Tomson $\mathrm{T}$. The pharmacological treatment of epilepsy inadults. Lancet Neurol. 2011;10(5):446-56.

6. Rossetti $\mathrm{AO}$, Lowenstein $\mathrm{DH}$. Management of refractory status epilepticus in adults: still more questions than answers. Lancet Neurol. 2011;10(10):922-30.

7. Wilder RM. The effects of ketonemia on the course of epilepsy. Mayo ClinBulletin. 1921;2:307-8.

8. Freeman JM, Kossoff EH, Freeman JB, Kelly MT. The ketogenic diet: a treatment for epilepsy in children and others. 4th ed. New York: Demos; 2006.

9. Elia M, Klepper J, Leiendecker B, Hartmann H. Ketogenic diets in the treatment of epilepsy. Curr Pharm Des. 2017;23(37):5691-701.

10. Juhl CB, Pørksen N, Sturis J, Hansen AP, Veldhuis JD, Pincus S, et al. Highfrequency oscillations in circulating amylin concentrations in healthy humans. Am J Physiol Endocrinol Metab. 2000;278(3):E484-90.

11. Hull RL, Westermark GT, Westermark P, Kahn SE. Islet amyloid: a critical entity in the pathogenesis of type 2 diabetes. J Clin Endocrinol Metab. 2004; 89(8):3629-43

12. Kong MF, Stubbs TA, King P, Macdonald IA, Lambourne JE, Blackshaw PE, et al. The effect of single doses of pramlintide on gastric emptying of two meals in men with IDDM. Diabetologia. 1998;41(5):577-83.

13. Vella A, Lee JS, Camilleri M, Szarka LA, Burton DD, Zinsmeister AR, et al. Effects of pramlintide, an amylin analogue, on gastric emptying in type 1 and 2 diabetes mellitus. Neurogastroenterol Motil. 2002;14(2):123-31.

14. Banks WA, Kastin AJ, Maness LM, Huang W, Jaspan JB. Permeability of the blood-brain barrier to amylin. Life Sci. 1995;57(22):1993-2001.

15. van Rossum D, Ménard DP, Fournier A, St-Pierre S, Quirion R. Autoradiographic distribution and receptor binding profile of [125l]Bolton Hunter-rat amylin binding sites in the rat brain. J Pharmacol Exp Ther. 1994; 270(2):779-87.

16. Sexton PM, Paxinos G, Kenney MA, Wookey PJ, Beaumont K. In vitro autoradiographic localization of amylin binding sites in rat brain. Neuroscience. 1994;62(2):553-67.

17. Moon HS, Chamberland JP, Mantzoros CS. Amylin and leptin activate overlapping signalling pathways in an additive manner in mouse GT1-7 hypothalamic, $C_{2} C_{12}$ muscle and AML12 liver cell lines. Diabetologia. 2012; 55(1):215-25.

18. May PC, Boggs LN, Fuson KS. Neurotoxicity of human amylin in rat primary hippocampal cultures: similarity to Alzheimer's disease amyloid-beta neurotoxicity. J Neurochem. 1993;61(6):2330-3. 
19. Wang E, Zhu H, Wang X, Gower AC, Wallack M, Blusztajn JK, et al. Amylin treatment reduces neuroinflammation and ameliorates abnormal patterns of gene expression in the cerebral cortex of an Alzheimer's disease mouse model. J Alzheimers Dis. 2017;56(1):47-61.

20. Westermark P, Andersson A, Westermark GT. Islet amyloid polypeptide, işlet amyloid, and diabetes mellitus. Physiol Rev. 2011;91(3):795-826.

21. Janciauskiene $\mathrm{S}$, Ahrén B. Fibrillar islet amyloid polypeptide differentially affects oxidative mechanisms and lipoprotein uptake in correlation with cytotoxicity in two insulin-producing cell lines. Biochem Biophys Res Commun. 2000; 19; 267(2):619-625.

22. Wendt T, Tanji N, Guo J, Hudson BI, Bierhaus A, Ramasamy R, et al. Glucose, glycation, and RAGE: implications for amplification of cellular dysfunction in diabetic nephropathy. J Am Soc Nephrol. 2003;14(5):1383-95.

23. Dimsdale JE, Kolterman O, Koda J, Nelesen R. Effect of race and hypertension on plasma amylin concentrations. Hypertension. 1996;27: $1273-6$.

24. Valdemarsson $S$, Leckstrom A, Westermark P, Bergenfelz A. Increased plasma levels of işlet amyloid polypeptide in patients with primary hyperparathyroidism. Eur J Endocrinol. 1996;134:320-5.

25. Ludvik B, Clodi M, Kautzky-Willer A, Schuller M, Graf H, Hartter E, et al. Increased levels of circulating islet amyloid polypeptide in patients with chronic renal failure have no effect on insulin secretion. J Clin Invest. 1994; 94:2045-50.

26. Despa S, Margulies KB, Chen L, Knowlton AA, Havel PJ, Taegtmeyer $\mathrm{H}$, et al. Hyperamylinemia contributes to cardiac dysfunction in obesity and diabetes: a study in humans and rats. Circ Res. 2012;110(4):598-608.

27. Jeong HR, An SS. Causative factors for formation of toxic islet amyloid polypeptide oligomer in type 2 diabetes mellitus. Clin Interv Aging. 2015;10: 1873-9.

28. Aronoff SL, Berkowitz K, APRN K, Shreiner B, Want L. Glucose metabolism and regulation: beyond Insulin and glucagon. Diabetes Spectrum. 2004;17: 183-90.

29. Misra M, Bredella MA, Tsai P, Mendes N, Miller KK, Klibanski A. Lower growth hormone and higher cortisol are associated with greater visceral adiposity, intramyocellular lipids, and insulin resistance in overweight girls. Am J Physiol Endocrinol Metab. 2008;295(2):385-92.

30. Gong W, Liu ZH, Zeng CH, Peng A, Chen HP, Zhou H, et al. Amylin deposition in the kidney of patients with diabetic nephropathy. Kidney Int. 2007;72(2):213-8.

31. Jackson K, Barisone GA, Diaz E, Jin LW, DeCarli C, Despa F. Amylin deposition in the brain: a second amyloid in Alzheimer disease? Ann Neurol. 2013;74(4):517-26.

32. Mulder $\mathrm{H}$, Leckström $\mathrm{A}$, Uddman $\mathrm{R}$, Ekblad E, Westermark $\mathrm{P}$, Sundler F. Islet amyloid polypeptide (amylin) is expressed in sensory neurons. J Neurosci. 1995;15(11):7625-32.

\section{Publisher's Note}

Springer Nature remains neutral with regard to jurisdictional claims in published maps and institutional affiliations.

\section{Submit your manuscript to a SpringerOpen ${ }^{\circ}$ journal and benefit from:}

- Convenient online submission

- Rigorous peer review

- Open access: articles freely available online

- High visibility within the field

- Retaining the copyright to your article

Submit your next manuscript at $\boldsymbol{\nabla}$ springeropen.com 